\title{
5. The Procedural School: A Critical Analysis
}

\begin{abstract}
In this chapter, I undertake a critical review of the literature that has contributed to understanding how games can be used to convey advertising messages. This literature review is organized around Bogost's theory on procedural rhetoric due to the high relevance of the procedural school to the study of digital games' persuasiveness. This literature review is used to pinpoint the statements of other scholars on the topic of persuasion through digital games with which I agree or disagree. This is done to gather and develop the main arguments that allow me to outline a theoretical model for the study of how persuasive messages can be conveyed through digital games.
\end{abstract}

Keywords: procedural school, persuasive games, procedural rhetoric, critical literature review, advergames

As briefly mentioned above, the first two books by Bogost $(2006,2007)$ were the starting point for the procedural school, followed not just by academics (e.g. Brathwaite \& Sharp, 2010; Colby, 2014; Flanagan, 2009; Mateas, 2005; Seiffert \& Nothhaft 2015; Swain, 2010; Treanor \& Mateas, 2009), but also by the game industry. In his book Persuasive Games: The Expressive Power of Videogames, the author contends that, as procedural environments, digital games open up a new domain for persuasion (Bogost 2007, preface viii). However, different authors have found shortcomings in Bogost's claims (e.g. Ferrari, 2010; Heide \& Nørholm Just, 2009; Sicart, 2011). In 2011, the game scholar Miguel Sicart published an article 'Against Procedurality' that has initiated a debate about the validity of proceduralism. In his article, Sicart claims that while proceduralists argue that the rules of the game create the meaning, actually the "meaning of a game cannot be reduced to its rules, nor to the behaviors derived from the rules, since play will be a process of

De la Hera, Teresa, Digital Gaming and the Advertising Landscape. Amsterdam: Amsterdam University Press, 2019.

DOI 10.5117/9789462987159_CHO5 
appropriation of those rules, a dialogue between the system and the player" (2011, para. 57). Due to the high relevance of the procedural school to the study of digital games' persuasiveness and the significance this debate has acquired within the field of game studies, I have decided to organize this literature review around Bogost's statements.

This chapter is divided into three main sections. In the first section, I undertake a short review of previous research on persuasive communication that allows me to identify how and when the academic study of persuasiveness in digital games started and the importance of the procedural school to this field. Then, I focus my attention on Bogost's statements, dividing my critical analysis into two parts: firstly, Bogost's definition and study of persuasive games, and secondly Bogost's application of his theory about persuasive games to the domain of advergames.

\section{Previous Research on Persuasive Communication}

Previously, I have argued that an advergame is a digital game specifically designed for a brand with the purpose of conveying an advertising message. Thus, a digital game is the medium selected by a brand to convey an advertising message in the communication process it establishes with its customers. Furthermore, I have stated that advertising messages within advergames can be focused on affecting players' feelings, attitudes, and/or behaviors toward a brand or a product and can be aimed at building brand identity, changing existing perceptions of the brand or product, or generating a trial purchase.

According to the communication scholar Gerald R. Miller, any message that is aimed at shaping, reinforcing, or changing the perceptions, emotions, beliefs, behavioral intentions, and behaviors is to be considered as persuasive communication (2002, p. 7). Therefore, the purpose of advergames is to convey persuasive messages that intentionally aim to affect the responses of another or others.

The study of persuasive communication began in Ancient Greece and has a history of more than two millennia. Plato and Aristotle framed rhetoric as a technique for oral persuasion, followed by the notable Roman scholars Quintillian and Cicero. It was Cicero who described rhetoric as a "speech designed to persuade" (quoted in Burke, 1969, p. 49). Many centuries later, the development of mass media facilitated the broadening of the concept of rhetoric beyond oratory.

Although the focus of the study of persuasive communication has been overwhelmingly focused on verbal strategies, the development of film, 
television, and visual advertisement have favored the expansion of the term. The philosopher Kenneth Burke (1987-1993) was the first to acknowledge the persuasive potential of non-verbal domains. "Wherever there is persuasion," he wrote, "there is rhetoric. And wherever there is 'meaning,' there is 'persuasion'." (Burke, 1969, p. 172). Burke's work gave rise to the study of persuasiveness in other domains, increasing interest in visual rhetoric, understood as the art of using imagery and visuals persuasively. A significant contribution to this field is Roland Barthes' 1977 essay 'Rhetoric of the Image', which provides insight into the way advertising images may contain meaning. However, although the study of visual rhetoric has served to reveal the persuasive potential of many non-verbal domains, game scholars (e.g. Bogost, 2007; Ferrari, 2010; Frasca, 2007) have identified unique properties of digital games that deserve special attention in order to understand the way they convey meaning.

The game scholar Gonzalo Frasca identified in 2001 the potential of digital games as a "medium for fostering critical thinking and discussion about social and personal problems" (2001, summary ix). Later, the author defended his PhD thesis Play the Message. Play, Game and Videogame Rhetoric (Frasca, 2007) in which he proposed a framework for analyzing game rhetoric that aims to explain how games convey meaning.

However, it was not until the publication of Ian Bogost's book Persuasive Games: The Expressive Power of Videogames (2007) that academics began to investigate the way digital games convey advertising messages. In his book, the author argues that as procedural environments, digital games open up a new domain for persuasion (Ibid., preface viii). Bogost claims that digital games are not "characterized by their ability to carry images, but by their capacity for operationalizing rules" (Ibid., p. 171) and defines the term procedural rhetoric by explaining what he identifies as the "unique persuasive powers" (Ibid., preface ix) of digital games and the way they build arguments and influence players.

The term procedural rhetoric comes from the union of two concepts: procedurality and rhetoric. Bogost defines procedurality as the "way of creating, explaining or understanding processes" and processes as the "methods, techniques and logics that drive the operation of systems" (Ibid., p. 2). Therefore, procedural rhetoric refers to the power of computational systems to make persuasive arguments. Bogost calls procedural rhetoric "the art of persuasion through rule-based representations and interactions rather than the spoken word, writing, images or moving pictures" (Ibid., preface ix). He considers advertising as a possible domain to apply procedural rhetoric and advergames a category of persuasive games (Ibid., p. 46). 
Since the publication of Bogost's first two books (2006, 2007), procedural rhetoric has been the focus of attention of many scholars working on persuasive strategies in digital games (e.g. Ferrari, 2010; Flanagan, 2010; Heide \& Nørholm Just, 2009; Swain, 2007). What interests proceduralists is the way in which symbol manipulation of processes that initially appear unexpressive may result in a higher order of expression. However, some authors have identified shortcomings in the proceduralists' assertions (e.g. Ferrari, 2010; Heide \& Nørholm Just, 2009; Sicart, 2011). Due to the high relevance of proceduralism to the study of digital games persuasiveness, I have conducted a critical literature review around Bogost's arguments in which I use the shortcomings found by other scholars to inform my claims and propose a new approach for the study of persuasive communication within digital games.

\section{Ian Bogost on Persuasive Games}

As previously explained, Bogost assumes that persuasive games are digital (2007, p. 171) and suggests that the procedural nature of digital games differentiates them from other types of persuasive media. For that reason, the author considers that previous theories on persuasive communication, such as visual rhetoric, are not valid for understanding how digital games can be used to convey persuasive messages. Bogost claims that the capacity of digital games to operationalize rules opens a new domain for persuasion, and he chooses the term procedural rhetoric to refer to the art of persuasion through rule-based representations (Ibid., preface viii).

Bogost starts by stating that, in procedural media such as digital games, "images are frequently constructed, selected, or sequenced in code", which subordinates them to the game process (Ibid., p. 25). Following this reasoning, the author defines persuasive games as digital games "that mount procedural rhetoric effectively" (Ibid., p. 46), from which it can be concluded that Bogost assumes that persuasiveness in digital games completely relies on procedural rhetoric and that other persuasive dimensions are always subordinated to procedural rhetoric in procedural media.

Bogost's theory is grounded in his statement that, of all essential properties of digital games identified by Murray (Ibid., p. 71), procedurality alone is unique to the digital. The author considers that procedurality is the principal value of digital games because even though procedurality can be read in both computational and noncomputational structures, "computational procedurality places a greater emphasis on the expressive capacity afforded 
by rules of execution" (Ibid., p. 4). In order to support his statement on the expressive capacity of digital games as persuasive environments, Bogost draws on their capacity to change player beliefs and attitudes by favoring the creation of mental images in players (Ibid., p.35). To defend this assertion, Bogost appeals to Hill's notion of vividness.

Vividness is defined by the rhetorician Charles A. Hill as "the relationship between the creation of mental images through reading text and the process of developing or revising one's beliefs and attitudes based on this mental images" (2004, p. 31). Hill points out that images offer greater vividness than verbal narration or written description and proposes a continuum of vividness in which the actual experience is considered the most vivid type of information, followed by moving images with sound, static photography, realistic painting, line drawing, narrative, descriptive account, abstract analysis, and statistics. The author refers to a study conducted by Smith and Shaffer (2000) to assert that vivid language "makes a persuasive message easier to comprehend and more likely to be remembered" if the "vivid elements are clearly and explicitly relevant to the message itself" (Hill, 2004, p. 32).

Bogost (2007, p. 35) states that procedural representations seem to increase the persuasive properties Hill attributes to vividness. Furthermore, Bogost claims that procedural representations with high process intensity ${ }^{1}$ and with meaningful symbolic representations in their processes, especially digital games, should be considered the most vivid type of information after actual experience. In this regard, the media scholars Jonas Heide and Sine Nørholm Just have argued that vivid representations are actually essentially the same as other persuasive forms (2009, p. 57) and their effectiveness will depend on the specific features of each campaign. As with other persuasive forms, the procedural mode of persuasion may hold a potential that is not always fully realized.

However, although Bogost claims that procedurality is the only property of digital games unique to the digital, he later contradicts himself when he refers to the potential of sophisticated interactivity - another of the properties mentioned by Murray (1997, p. 71) - to empower procedural rhetoric within persuasive games (Bogost, 2007, p. 43). Bogost refers to the

1 Chris Crawford defines process intensity as the "degree to which a program emphasizes processes instead of data" $(1987$, p.1). Process here refers to the algorithms and equations a program processes; and data refers to data tables, images, sounds, and text. "A process-intensive program spends a lot of time crunching numbers; a data-intensive program spends a lot of time moving bytes around", Crawford (1987, p.1) explains. 
Aristotelian enthymeme in order to explain the potential of sophisticated interactivity within persuasive games. Aristotle uses the term enthymeme to refer in rhetoric to the equivalent of deduction in human reasoning (1979, p. 32). Consequently, in rhetorical enthymemes the orator omits a proposition that is deduced by the listener from accepted opinions.

Following Bogost's reasoning, in digital games sophisticated interactivity can be used to formulate enthymemes leading the player to fill in a proposition suggested by the rules. The author calls the gap between the rule-based representation of the game and the player subjectivity the "simulation gap" ( 2007, p. 18). Bogost suggests that, as a procedural environment, a digital game can be seen as a "system of nested enthymemes, individual procedural claims that the player literally completes through interaction" (Ibid., p. 43). Therefore, the author argues that procedural rhetoric can be empowered by sophisticated interactivity favoring deductive reasoning in players, who are guided to fill in the simulation gaps between the rule-based representation of the game and player subjectivity. Consequently, Bogost claims that players' behavior and interpretation within digital games can be suggested by the rules and guided by sophisticated interactivity. However, Heide and Nørholm Just claim that Bogost's arguments do nothing other than show that participation is inherent in the process of persuasion itself and that it is not unique to procedural rhetoric (2009, p. 57).

Furthermore, guiding players' behavior through rules is not as simple as Bogost presents it. According to the game scholar Simon Ferrari, one of Bogost's flaws is to presume the existence of ideal players who play the game in a way the game designer is expecting them to play it (2010, p. 2). However, there is no single correct way to complete an enthymeme. Although the rules of digital games usually cannot be discussed and changed during play, because they are normally authored in a code that is inaccessible to players (Sicart, 2009, p. 27), it has been demonstrated by empirical research that, when possible, players enjoy adopting their own rules and disregarding the designed ones (see Taylor, 2009). Moreover, the more complex a game gets, the more difficult it becomes to predict the player's performance and, simultaneously, the range of meanings the game affords widens (Ferrari, 2010, p. 2).

Bogost contradicts himself when, on the one hand, he argues that digital games are the most procedural artifacts because they are the most capable of serving representational goals compared to other types of computational media (2007, p. 45). On the other hand, as Sicart points out, he discounts player expression, turning play into an instrumental action (2011, p. 7). In this sense, following the game scholar Simon Ferrari's arguments, Bogost 
is ignoring players' creativity and forgetting that players' choices can lead to a manipulation of the dominant rhetoric intended by the game designer (2010, preface $\mathrm{x}$ ), resulting in a misunderstanding of the proposition omitted in the syllogisms. The consequences of this problem in an advergame would be that the player would not understand the advertising message in the way intended.

Additionally, the limitation of interactivity with the intention of guiding players' behavior minimizes the sense of pleasure while playing digital games. Murray (1997) states that the sense of pleasure is enhanced within digital games by three properties: immersion, the pleasurable "experience of being transported to an elaborately simulated place" (Ibid., p. 98); agency, "the satisfying power to take meaningful action and see the results of out of decisions and choices" (Ibid., p. 126); and the pleasure of transformation characteristic of digital environments (Ibid., p. 154). The consequence of disregarding players' creativity is the absence of the pleasurable experience of agency and a limitation of the pleasurable experience of transformation.

Games produced and analyzed under the proceduralist domain are closed systems in which play is predictable, which makes them unbalanced, and the game's balance is determinant in keeping the player in the game. A balanced game is "one where the main determining factor for the success of the player is the skill level of that player" (Rollings \& Adams, 2003, p. 240), which means that a better skilled player should be more successful than a less able player. A game containing an active balance will be able to "either increase difficulty or to adapt the games to the ability of the player" (Ibid., p. 267). Balancing a game is useful to avoid stagnation ${ }^{2}$ - one of the main reasons people stop playing - to avoid trivialities, to allow a setting of the difficulty level, to provide a consistent challenge and to provide the player with a perceivably fair playing experience (Ibid., p. 271). Games in which play is predictable and creativity is limited are unbalanced and therefore, following one of Sicart's criticisms of games produced under the proceduralist domain, "too rigid, obvious and banal" to make users want to play them (2011, p. 11). Consequently, if games produced and analyzed under the proceduralist domain are not attractive for players, it is difficult for them to be useful to support proceduralist arguments.

I would conclude that Bogost's statements on procedural rhetoric are useful in showing how arguments can be embedded in the rules of a digital game. However, the procedural nature of digital games is not the only

2 "Stagnation occurs when players are playing a game and reach a point where they appear to be stuck, with no way to go on" (Rollings \& Adams, 2003: 271). 
game characteristic that can be used to convey persuasive messages. As digital games, advergames are also spatial, interactive, encyclopedic, and networked environments, and these characteristics can also be exploited with persuasive intentions. Furthermore, the limitation of players' creativity in order to guide players' behavior reduces the sense of pleasure during the game session and results in unbalanced games. Therefore, other persuasive dimensions should complement procedural rhetoric with the objective of providing meaningful pleasurable experiences. As will be further explained in chapter 6, the use of other persuasive dimensions within digital games facilitates the design of games that respect players' creativity and provide freedom to the players to experience unique and unrepeatable experiences as the result of their own performance. At the same time, this freedom does not need to become an obstacle to the persuasive process.

Consequently, persuasive games should not be defined as digital games "that mount procedural rhetoric effectively" (Bogost, 2007, p. 46). Instead, following Miller's (2002) definition of persuasive communication, I suggest defining persuasive games as digital games that aim to shape, reinforce, or change the perceptions, emotions, beliefs, behavioral intentions, and behaviors of players.

\section{Ian Bogost on Advergames}

Bogost considers advertising a domain where one can apply procedural rhetoric and therefore considers advergames as a category of persuasive games (2007, p. 46). Following this reasoning, the author argues that advergames are "created specifically to host a procedural rhetoric about the claims of a product or service" and proposes to define them as "simulations of products and services" (Ibid., p. 200). However, I would maintain that Bogost's definition of advergames is inaccurate as a result of his erroneous definition of persuasive games, as I will explain below.

I argued above that persuasive games cannot simply be defined as digital games "that mount procedural rhetoric effectively" (Ibid., p. 46), but following Miller's (2002) definition of persuasive communication, as digital games that aim to shape, reinforce, or change the perceptions, emotions, beliefs, behavioral intentions, and behaviors of players. Furthermore, I have stated that the purpose of advergames is to convey persuasive messages that intentionally aim to affect the responses of another or others. Therefore, advergames can be considered a category of persuasive games in the sense that they are understood in this text. 
Following the arguments presented in the previous section, advergames, as persuasive games, can make use of the procedural nature of digital games as well as of the other unique digital-game characteristics to persuade players: their interactivity; their networked communication; their capacity to hold and manipulate information; and their power to represent spaces through which players can navigate. It follows that advergames are not created specifically to host a procedural rhetoric but to persuade players. For that purpose, advergames can use procedural rhetoric or any other persuasive dimension favored by another of their properties. In the next chapter, I will explain in detail all the persuasive dimensions that can be exploited in digital games.

Additionally, Bogost argues that, within advergames, the overlap between the game goal and the learning goal is more persuasive than their complete separation (2007, p. 16o). Though this overlap can make sense in games with educational purposes, it is not so logical for advergames (Heide \& Nørholm Just, 2009, p. 59). In an educational game trying to teach history, for instance, it would be a good idea not to allow the player to succeed in the game without actually having learned the lesson. However, the same strategy could be difficult to achieve if the purpose of an advergame is to change players' attitudes or behaviors, because a player can act to agree with the point of the game in order to win it without actually changing his beliefs or actions in the physical world. Moreover, it is important to underline that advertising messages are usually unwanted communication (Messaris, 1997, p. 5). Therefore, in order to avoid players' resistance, the persuasive intentions of the game should not be as obvious as the persuasive intentions of an educational game. It follows that, though Bogost approaches the study of political games, educational games, and advergames from the same point of view, the fact is that digital games with advertising purposes differ from those with educational or political purposes, and their persuasive strategies have particular qualities that should be studied separately.

Furthermore, when Bogost asserts that advergames are "simulations of products and services" (2007, p. 200), he is grounding his definition in his argument that they are specifically created to host a procedural rhetoric about the claims of a product or service (Ibid., p. 200). However, as previously argued, digital games can convey advertising messages not only through their rules, but also through other persuasive dimensions.

Moreover, Bogost's definition of advergames is supported by his claim that advergames that try to "correlate advertising messages with the actual features and functions of goods and services" fit better with the properties of the digital-game medium than do advergames, which attempt 
to "manufacture needs in consumers by suggesting affinities between aspirations and brands" (Ibid., preface $\mathrm{x}$ ). Nevertheless, this assertion does nothing other than show that Bogost is ignoring any expressive capacity of digital games beyond the procedural, as I explain below.

Correlating advertising messages with the actual features and functions of goods and services implies assuming that consumer preferences reflect rational decisions. This approach takes for granted that consumers are able to differentiate products according to their characteristics and that they use rational thinking to make decisions and to differentiate the offers made by one company from those made by its competitors. This strategy focuses on specific product properties and uses analytical, quantitative, and rhetoric methods to convince consumers. However, although Bogost asserts that this strategy is the one that better fits with the properties of the digital-game medium, the fact is that the use of this strategy in digital games entails a series of difficulties compared to its use in other advertising media. These difficulties are related to (1) information overload, (2) channel noise, and (3) semantic noise.

1. Information Overload: One of the unique properties of digital games as media for advertising is that they have the potential to contain large amounts of information encyclopedically, which can be selectively revealed at appropriate places during play (Salen \& Zimmerman, 2004, p. 88). However, researchers in consumer behavior Jacoby, Speller, and Kohn have demonstrated that consumers can make poorer purchasing decisions when they are provided with more information because they can feel overloaded (Jacoby, Speller, \& Kohn, 1974, p.69). Consequently, consumers tend to use information-processing strategies to limit the amount of information that they process to make purchasing decisions (Ibid., p. 434). Therefore, advergames should not be designed to force players to process large amounts of information. Rather, advergames should permit the player to access and reject information at will. For that purpose, as complex automated systems, advergames can hide information from players and then reveal it at particular moments of the game session. This can allow brands to retrieve information from players' performance, which can be useful to convey customized messages to their consumers, avoiding information overload.

2. Channel Noise. The interactive nature of digital games makes players 'coauthors' of the advertising discourse. This means that advertisers cannot totally control the way players interpret the information hosted in the game or the particular meaning this information can acquire through 
players' performance. All this interactivity can result in channel noise, namely any distraction or distortion of the message caused by the way players interact with it (Narula, 2006, p. 27). In order to avoid channel noise within advergames, advertisers should not think about limiting players' freedom, because this can result in unappealing advergames in which players feel that their performance has no influence on the outcome of the game. Players who feel their actions are insignificant may become dissatisfied with the game and then link that disappointing feeling to their attitude toward the brand. Trying to completely control the way the message is conveyed is impossible within advergames due to their interactive nature. In addition, if there is any important idea that the brand needs to convey to players, advergames designers can make use of redundancy by repeating the main idea of the message in different parts of the advergame to reduce channel noise (Ibid., p.29). This can help designers to ensure that players do not miss the main idea, regardless of their performance within the game.

3. Semantic Noise: As encyclopedic systems, advergames can confound players by offering contradictory or incoherent information that produces semantic noise. Semantic noise in advergames occurs when the player does not ascribe the same meaning to the advertising message as the one intended by the advertiser (Shannon \& Weaver in Narula, 2006). When designing advergames it must be taken into consideration that not only those elements of the game that are intentionally designed to convey meaning are providing information to the user, but that every aspect of the advergame that can be regarded as information can contribute to the meaning the players ascribe to the advertising message. Therefore, advergame designers should pay attention to every aspect of the advergame when trying to convey an advertising message. Furthermore, players' feedback can be valuable within advergames to assess the effects of possible semantic noise. In that sense, advergames can use interactive actions to discover whether players understand the message in the way intended.

Furthermore, although Bogost contends that advergames that attempt to "manufacture needs in consumers by suggesting affinities between aspirations and brands" (preface $\mathrm{x}$ ) do not fit with the properties of digital games, advergames, as digital games, have the capacity to deploy pleasurable experiences that can be useful in conveying advertising messages that aim to influence players' attitudes or appeal to their emotions. This marketing approach, known as experiential marketing, considers that consumers do 
not think about specific products but rather about concrete situations in which they need solutions to specific problems or desires (see Schmitt, 2000). According to marketing scholar Bernd Schmitt (2000), irrational and emotional aspects involved in a purchasing decision have the same importance as the rational and logical elements. Experiential marketing is focused on delivering memorable experiences that produce emotions and also transformations in individuals. Implementing this marketing strategy within advergames consists of allowing consumers to "design their own meaningful experiences" (Norton, 2003, p. 24). However, delivering engaging experiences is not enough to achieve the advertising goals. When designing experiential marketing strategies for advergames, advertisers need to think about how to make them meaningful from the brand's perspective. Therefore, the brand has to become a part of the players' personal and meaningful experience.

An example of good understanding of how to use digital games to design branded experiences is the World's Worst War (Hakuhodo, 2007). This awardwinning multiplayer, online mobile advergame was launched to promote two new Tohato snack flavors: Tyrant Habanero Burning Hell Hot and Satan Jorquia Bazooka Deadly Hot. In the game, customers were encouraged to buy one of the two snacks in order to choose their Master. In the packet, they found an access code to join one of the two online armies with which they could fight a battle every day at 4 a.m. Players were able to choose their battlefield from 31 spots. The army that conquered all the battlefields won.

According to the developers, the game was so incredibly successful because of the social interaction. The player was able to get promotion in the army by recruiting friends as warriors under him, and this system spread the game all over the country. Players also started to meet up on social networks to develop strategies. In addition, there were war reporters who sent SMSes round the clock, adding reality to the game. Every new player was supposed to buy the product. Thus, sales and site accesses increased dramatically to 100,000 page views per day.

World's Worst War featured most of the ingredients that make a branded experience a success. The consumers not only approached the experience voluntarily, but they bought the product before being involved in the experience. Once in the game, it turned into such a meaningful experience for them that they were willing to wake up in the middle of the night to join a battle. In addition, the players themselves spread the word about the game in order to recruit warriors. It was such an engaging experience that they voluntarily spent extra time meeting their friends on social media to develop strategies, which meant extra time dedicated to talking about the 
brand and the meaningful experience they were enjoying. And all those positive feelings were inevitably associated with the brand, helping to build the brand's image.

It can be concluded that the use of emotion strategies within advergames can be useful in designing meaningful experiences that take advantage of the expressive capacities of digital games. These strategies can be particularly useful when consumers have sufficient information about the product advertised (Armstrong, 2010, p. 26). However, advergames that incorporate emotion strategies should not neglect players' creativity in order not only to initially attract players to the game, but also to engage them to keep playing. Also, when using experiential marketing strategies to convey advertising messages, it is important to find a way to make them meaningful from the brand's perspective.

Advergames should not be defined as "simulations of products and services" (Bogost, 2007, p. 200) that try to "correlate advertising messages with the actual features and functions of goods and services" (Ibid., preface $x$ ), because they are useful beyond conveying advertising messages that aim to provide information. Rather, advergames should be defined as digital games specifically designed for a brand with the aim of conveying an advertising message.

With the aim of exemplifying the points of my critical analysis of Bogost's statements, let us look more closely at the advergame Prune to Win (Fiskars, 2005), mentioned by Bogost as an example of how to mount procedural rhetoric effectively. The game was released with the purpose of presenting four of Fiskars' gardening tools. The player in the game needs to trim different plants growing in a garden. For that purpose, the player has to use four different Fiskars' gardening tools, each of them suitable for a particular plant. Trimming a plant with the appropriate tool increases the player's score. There is no outcome other than increasing the player's score and there is no possibility of leveling up; the game does not increase in difficulty or change the challenges after the first level.

It could be said that, from Bogost's perspective, Prune to Win has all the ingredients to effectively persuade the player. The game draws on procedural rhetoric to convey a message that the player can interact with, and that message is not received passively. The game also presents the highest level of product-game integration, letting the user interact with the product in its natural context. Furthermore, the game goal and the learning goal overlap, which implies that the player needs to understand the message in order to succeed in the game. However, Prune to Win is an advergame and not an educational game. The purpose of the game should be not only to make 
players understand the usefulness of the gardening tools, and maybe make them feel the need to buy them, but also to give players a clear understanding that, when purchasing gardening tools, the best option is Fiskars' products.

However, when playing the game, it is impossible to find any arguments to support the message that Fiskars is the brand to be purchased. It is impossible to know what Fiskars' gardening tools look like in the physical world: if they are light or heavy, or if they are made of a resistant material, for instance. Neither the gardening tools, nor the brand is related to a lifestyle with which the player could identify. Consequently, it could be concluded that the player may be persuaded to buy the gardening tools presented in the advergame but not specifically Fiskars' gardening tools. Players may understand that they need a pruning stick to trim a tree, but they do not have many reasons to look for a Fiskars' stick and thus may just buy the first pruning stick they find when they enter a store.

Furthermore, with the intention of guiding players' behavior through the rules of the game, Prune to Win limits the interactivity in the game, neglecting players' creativity. Additionally, the game is simple to play and also easy to master, and therefore is unbalanced. It does not challenge the player, who could be disappointed after playing it, which may be to the detriment of the brand's image. The final result is a game that is so obvious and banal that it is difficult to find reasons why a player would approach and play it.

The analysis of this advergame reveals that games following Bogost's theory may not be achieving their communication goals. Moreover, games designed under the proceduralist domain may be unattractive to players. The main problems of the application of Bogost's theory to advergames lie in ignoring any expressive capacity of digital games beyond the procedural and assuming that advergames can be designed like other types of persuasive games.

I suggest that the study of how persuasive messages can be conveyed through digital games should be addressed by taking into consideration all the possible dimensions that can be used within digital games to persuade players. Furthermore, I claim that the use of other persuasive dimensions can facilitate the design of persuasive games that respect players' creativity and provide freedom to the player to experience unique and unrepeatable experiences as a result of their own performance. In this sense, it is important to comprehend how all the different persuasive dimensions relate to each other, the issue central to chapter 6 . With this new approach, I aim to broaden the understanding of how persuasiveness can be implemented within digital games, which is of great relevance for the study of advergames' effectiveness. 


\section{References}

Armstrong, S. J. (2010). Persuasive Advertising. New York: Palgrave MacMillan.

Barthes, R. (1977). 'Rhetoric of the Image'. In: R. Barthes (ed.), Image-Music-Text (pp. 32-51). London: Wm. Collins Sons and Co.

Bogost, I. (2006). Unit Operations: An Approach to Videogame Criticism. Cambridge, MA: MIT Press.

Bogost, I. (2007). Persuasive Games: The Expressive Power of Videogames. Cambridge, MA: MIT Press.

Brathwaite, B., \& Sharp, J. (2010). 'The Mechanic is the Message: A Postmortem in Process'. In: K. Schrier \& D. Gibson (eds), Ethics and Game Design. Teaching Values through Play (pp. 311-329). Hershey, PA: Information Science Reference.

Burke, K. (1969). A Rhetoric of Motives. Berkeley, CA: University of California Press.

Colby, R. (2014). 'Writing and Assessing Procedural Rhetoric in Student-Produced

Video Games', Computers and Composition, 31, 43-52.

Crawford, C. (1987). 'Process Intensity', Erasmatazz, 1 (5).

Ferrari, S. (2010). The Judgment of Procedural Rhetoric. Georgia Institute of Technology, Georgia. [PhD Thesis]

Fiskars. (2005). Prune to Win [Digital Game].

Flanagan, M. (2009). Critical Play. Radical Game Design. Cambridge, MA: MIT Press.

Flanagan, M. (2010). ‘Creating Critical Play’. In: R. Catlow, M. Garrett \& C. Morgana (eds), Artists Re:Thinking Games (pp. 49-53). Liverpool: Liverpool University Press.

Frasca, G. (2001). Videogames of the Oppressed: Videogames as Means for Critical Thinking and Debate. Georgia Institute of Technology, Georgia. [MsC Thesis]

Frasca, G. (2007). Play the message. Play, Game and Videogame Rhetoric. IT University Copenhagen, Copenhagen. [PhD Thesis]

Hakuhodo (2007). World's Worst War [Digital Game].

Heide, J., \& Nørholm Just, S. (2009). 'Playful Persuasion. The Rhetorical Potential of Advergames', Nordicom Review, 3o(2), 53-68.

Hill, C. A. (2004). 'The Psychology of Rhetorical Images'. In: C. A. Hill (ed.), Defining Visual Rhetorics (pp. 25-40). London: Lawrence Erlbaum Associates.

Jacoby, J., Speller, D. E., \& Kohn, C. A. (1974). 'Brand Choice Behavior as a Function of Information Load', Journal of Marketing Research, 11(1), 63-69.

Mateas, M. (2005). 'Procedural Literacy: Educating the New Media Practitioner', On The Horizon. Special Issue. Future of Games, Simulations and Interactive Media in Learning Contexts, 13(1), 101-111.

Messaris, P. (1997). Visual Persuasion. London: Sage Publications.

Miller, G. R. (2002). 'On Being Persuaded: Some Basic Distinctions'. In: J. P. Dillard \& M. Pfau (eds), The Persuasion Handbook: Developments in Theory and Practice. London: Sage Publications. 
Murray, J. (1997). Hamlet on the Holodeck. New York: Free Press.

Narula, U. (2006). Handbook of Communication. Models, Perspectives, Strategies. New Dehli: Atlantic.

Norton, D. W. (2003). 'Towards Meaninful Brand Experiences', Design Management Journal, 14(1), 19-25.

Rollings, A., \& Adams, E. (2003). Andrew Rollings and Ernest Adams on Game Design. Indianapolis, IN: New Riders.

Salen, K., \& Zimmerman, E. (2004). Rules of Play: Game Design Fundamentals. Cambridge, MA: MIT Press.

Schmitt, B. H. (200o). Experiential Marketing. Barcelona: Deusto.

Seiffert, J., \& Nothhaft, H. (2015). 'The Missing Media: The Procedural Rhetoric of Computer Games', Public Relations Review, 41(2), 254-263.

Sicart, M. (2009). The Ethics of Computer Games. Cambridge, MA: MIT Press.

Smith, S. M., \& Shaffer, D. R. (200o). 'Vividness Can Undetermine or Enhance Message Processing. The Moderating Role of Vividness Congruency', Personal and Social Psychology Bulletin, 26, 769-779.

Swain, C. (2007). 'Designing Games to Effect Social Change'. Paper presented at the DiGRA 2007 Conference.

Swain, C. (2010). 'The Mechanic is the Message: How to Communicate Values in Games through the Mechanics of User Action and System Response'. In: K. Schrier \& D. Gibson (eds), Ethics and Game Design. Teaching Values through Play (pp. 217-235). Hershey, PA: Information Science Reference.

Taylor, T. L. (2009). 'The Assemblage of Play', Games and Culture, 4(4), 331-339.

Treanor, M., \& Mateas, M. (2009). 'Newsgames: Procedural Rhetoric meets Political Cartoons'. Paper presented at the Breaking New Ground: Innovation in Games, Play, Practice and Theory. 